\title{
Nature of the Cytochrome $\boldsymbol{c}$ Molten Globule
}

Ekaterina V. Pletneva, Harry B. Gray*, and Jay R. Winkler*

Supporting Information

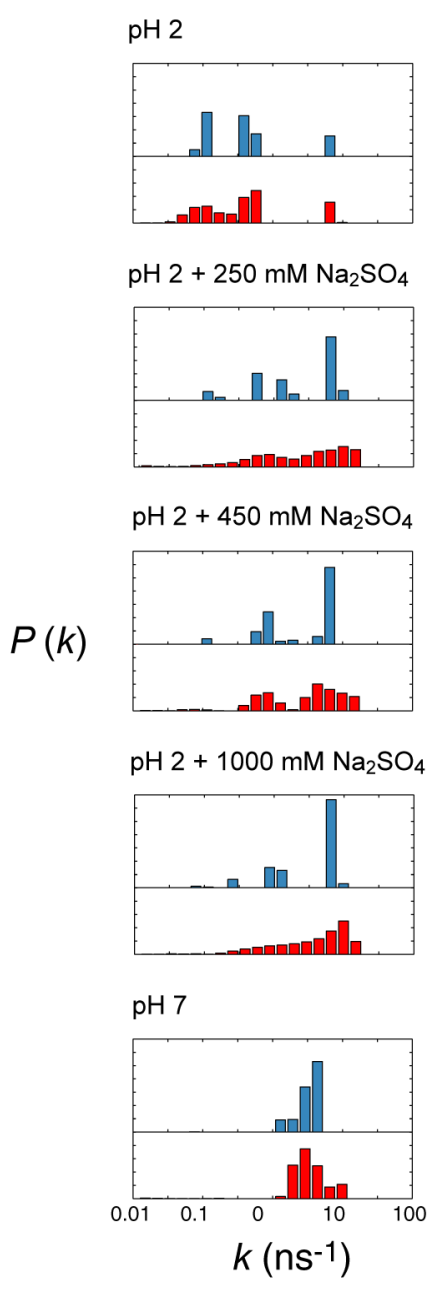

Figure S1. Distributions of fluorescence decay rates, $P(k)$, for Dns50cyt obtained with no inclusion of entropy $S$ parameter (LSQNONNEG analysis; blue) and with simultaneous minimization of $\chi^{2}$ and maximization of $S$ (ME analysis; red). 

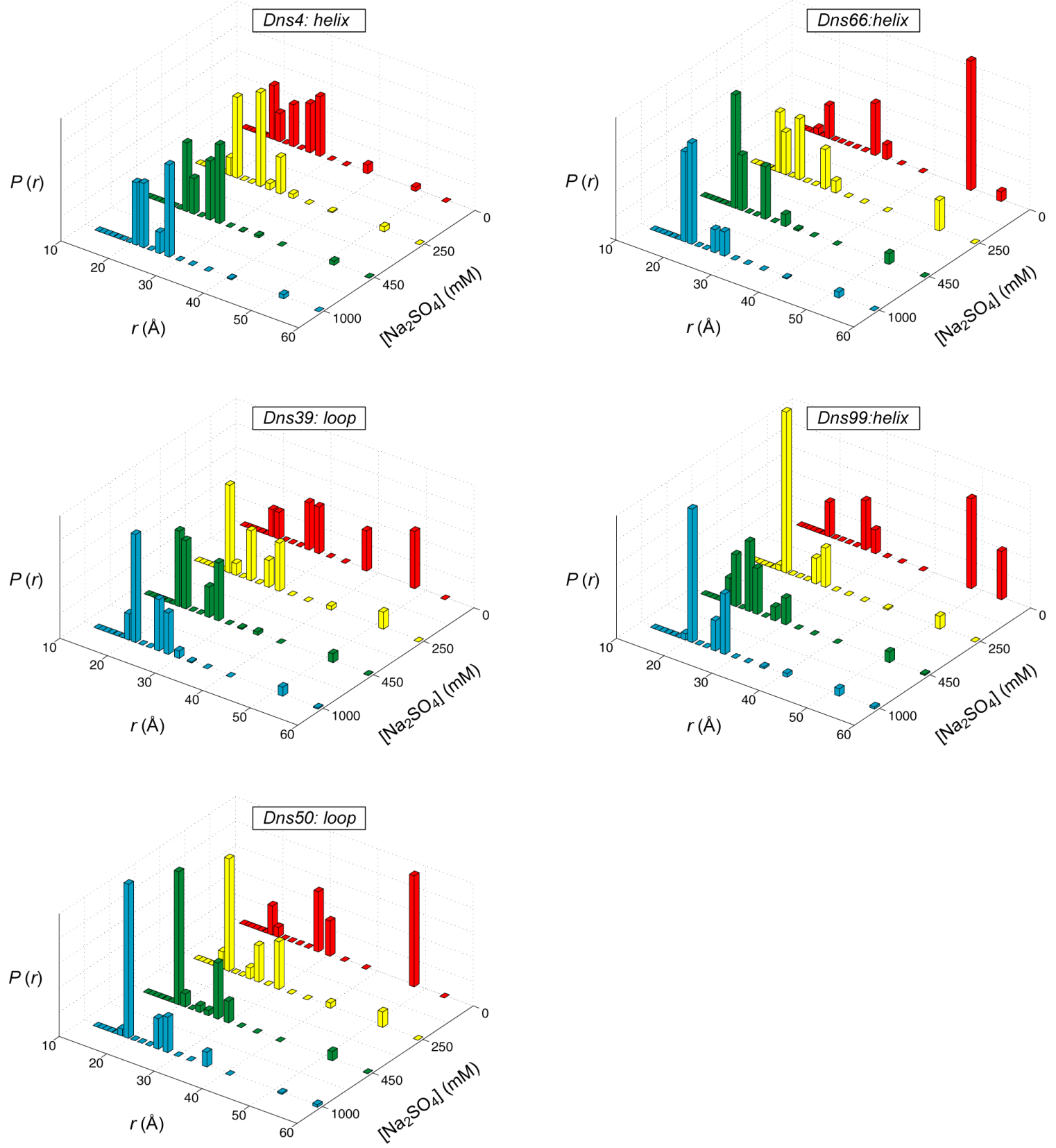

Figure S2. Distributions of $\boldsymbol{D}-\boldsymbol{A}$ distances, $P(r)$, for five Dns-labeled variants at $\mathrm{pH}$ 2.0, $18{ }^{\circ} \mathrm{C}$ and different concentrations of $\mathrm{Na}_{2} \mathrm{SO}_{4}$ from LSQNONNEG analyses of the FET kinetics. The analyses yielded lower limits for the distribution widths consistent with our data. 

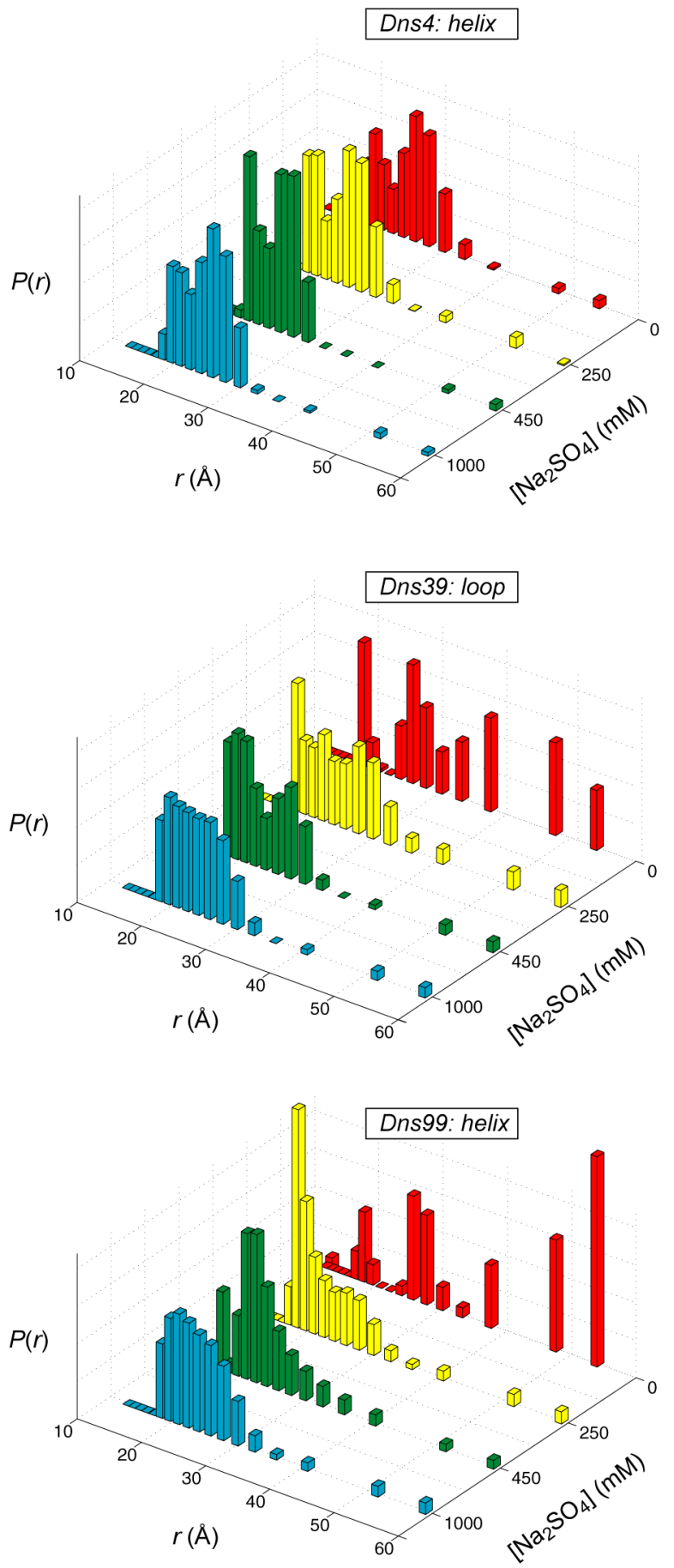

Figure S3. Distributions of $\boldsymbol{D}$ - $\boldsymbol{A}$ distances, $P(r)$, for Dns4cyt, Dns39cyt, and Dns99cyt at $\mathrm{pH} 2.0,18{ }^{\circ} \mathrm{C}$ and different concentrations of $\mathrm{Na}_{2} \mathrm{SO}_{4}$ from maximum-entropy analyses of the FET kinetics. The analyses yielded upper limits for the distribution widths consistent with our data. 

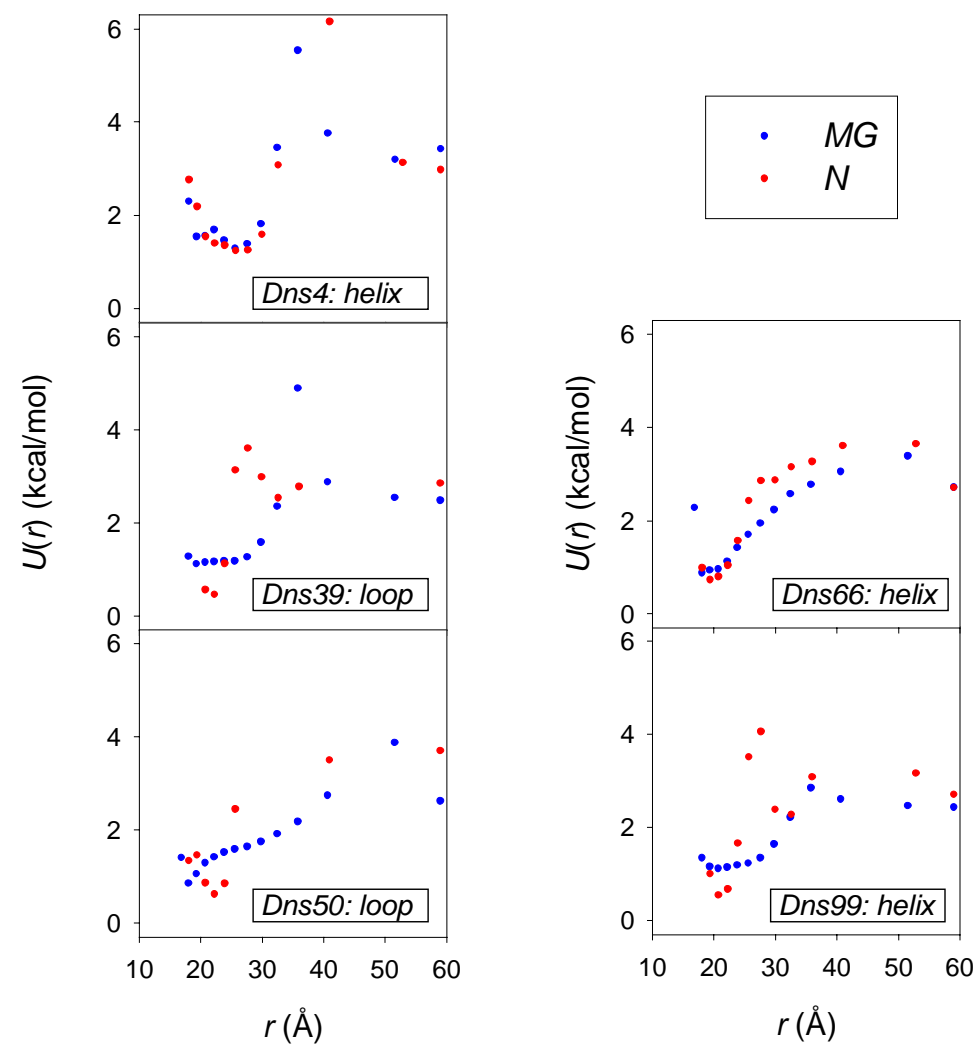

Figure S4. Experimental potential energy functions $U(r)$ (maximum-entropy analyses) for the molten globule at $\mathrm{pH} 2.0$ and $1.0 \mathrm{M} \mathrm{Na}_{2} \mathrm{SO}_{4}$ (blue) and for the native state at $\mathrm{pH} 7.0$ (red). 

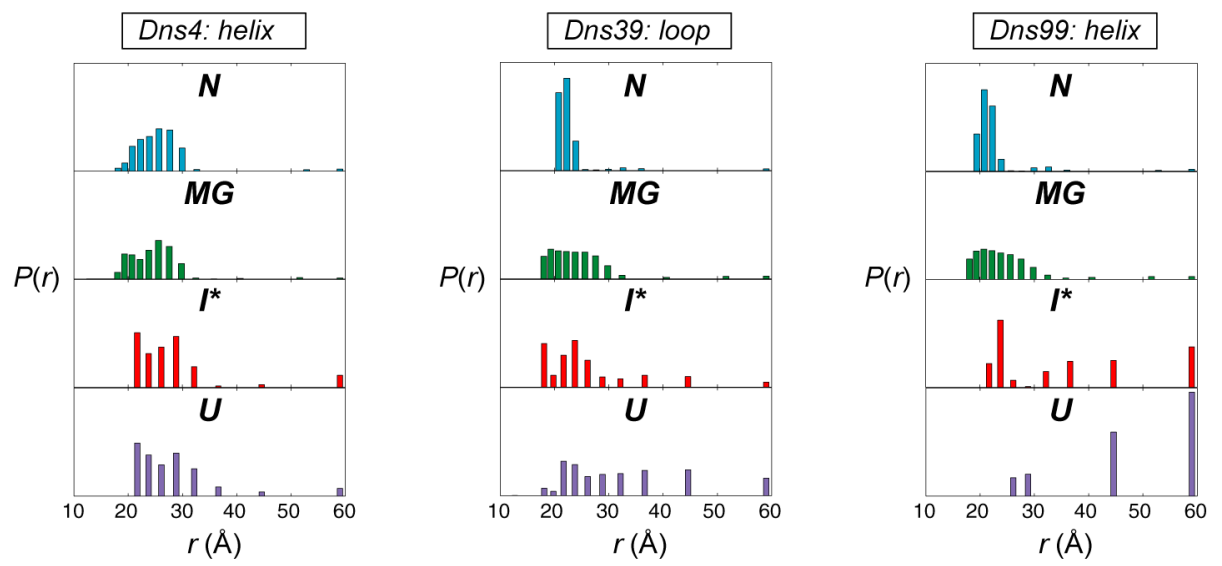

Figure S5. Distributions of $\boldsymbol{D}$ - $\boldsymbol{A}$ distances, $P(r)$, (maximum-entropy analyses) in Dns4cyt, Dns39cyt, and Dns99cyt for the native state at pH $7.0(\mathrm{~N})$; the molten globule, at pH 2.0 and $1.0 \mathrm{M} \mathrm{Na}_{2} \mathrm{SO}_{4}(\boldsymbol{M G})$; the transient species formed $1 \mathrm{~ms}$ after stopped-flow triggered refolding (0.2 $\mathrm{M} \mathrm{GuHCl}, 0.15 \mathrm{M}$ imidazole, $\mathrm{pH}$ 7.0) (I*); and the unfolded state at $2 \mathrm{M} \mathrm{GuHCl}, 0.15 \mathrm{M}$ imidazole, $\mathrm{pH} 7.0(\boldsymbol{U})$. The coarser spacing of the distance vector $\{r\}$ in the latter distributions arises from lower $\mathrm{S} / \mathrm{N}$ levels of the FET kinetics in single-shot compared to equilibrium measurements. 